\title{
Erratum to: Gamma Knife, CyberKnife or micro-multileaf collimator LINAC for intracranial radiosurgery?
}

\section{Thomas Mindermann}

Published online: 18 January 2015

(C) Springer-Verlag Wien 2015

\section{Erratum to: Acta Neurochir}

DOI 10.1007/s00701-014-2275-6

The original version of this article unfortunately contained mistakes.

Contrary to what is written in the article, it should read "in certain instances the dose rate may be as much as 5 times higher" in CK technology than in Gamma Knife technology (instead of "at least 5 times higher").

Also, the correct reference 6 should be:

6. Kaul D, Badakhshi H, Gevaert T, Pasemann D, Budach V, Tulaesca C, Gruen A, Prasad V, Levivier M, Kufeld M (2014) Dosimetric comparison of different treatment modalities for stereotactic radiosurgery of meningioma. Acta Neurochir. doi:10.1007/s00701-014-2272-9 